Code, 1959 ; Siegel and Hendrix, 1961). However, in the group of patients reported by Creamer et al. (1958) the analysis of motility studies suggests that synchronous activity occurred in the upper third in a higher percentage of swallows than the normal ; and Ellis et al. (1964) refer to the effects of operation on the disordered motility in the upper third in some patients. Abnormal contractions in the striated as well as the smooth muscle may suggest that the basic lesion is vagal overactivity rather than intrinsic disease of muscle.

The absence of any motility disorder demonstrated by radiology in four patients is in accordance with the findings of Ellis et al. (1964), and seems to emphasize that motility studies are important in the diagnosis of this condition. Several of our most severely affected patients had absent or minimal radiological findings and may have escaped diagnosis and effective treatment had motility studies not been performed.

Patients with a hypertensive lower oesophageal sphincter with peristaltic activity in the body of the oesophagus have been excluded from this analysis. However, three of the patients reported with diffuse spasm also had a high resting pressure in the lower oesophageal sphincter, which relaxed normally on swallowing and may be regarded as having both diseases. One of these patients has been operated on with complete abolition of symptoms. Of the 40 patients treated by oesophagomyotomy by Ellis et al. (1964) six suffered from this combination of diseases and all had excellent or good results.

The variable severity of diffuse spasm and the rapidity with which symptoms reached a plateau are of interest. There is a spectrum of severity from occasional symptoms which may be little more than a source of embarrassment or irritation to a disease which makes work impossible and may threaten life. At all grades of severity the symptoms develop fairly rapidly over a few months to a level which, once attained, remains constant. Inexorable progression from mild to severe disease was not encountered in this study.

The mildly affected patients have gained little relief from alkalis or anticholinergics. Reports from earlier literature of the benefits obtained from nicotinic acid and papaverine have not been sybstantiated in recent years.

The severely affected patients have undoubtedly benefited from surgery, and have been free from postoperative complica- tions. The motility studies of all the severely affected patients had a high proportion of swallows showing spontaneous repetitive activity and pressures up to $120 \mathrm{~mm}$. $\mathrm{Hg}$ after swallowing. However, in some of the patients managed conservatively similar severe changes were present. Thus in our experience it is impossible to judge the severity of the disease entirely on the motility changes. For this reason no patient has been subjected to thoracotomy unless completely incapacitated by symptoms. Under these circumstances long oesophagomyotomy is justified, and the patient can be assured of relief.

\section{Summary}

The diagnosis of diffuse oesophageal spasm was made in 21 patients on the basis of a history of intermittent episodes of dysphagia and chest pain, and the replacement of peristalsis by synchronous, often repetitive or prolonged and spontaneous activity on oesophageal motility. Synchronous activity was present in the upper oesophagus in 16 patients, and repetitive and prolonged pressure rises were present in 10. Eight patients were under the age of 40 , seven between 40 and 60, and six over 60. There was an equal sex distribution at all ages. Seven patients, evenly distributed throughout the age groups, were severely disabled by their symptoms, and were subjected to long oesophagomyotomy with relief of symptoms. Thickened oesophageal muscle containing ganglion cells and an inflammatory infiltrate was found on operation to extend from the cardia up to and beyond the arch of aorta.

\section{REFERENCES}

Code, C. F. (1959). Postgrad. Med., 26, 265

Creamer, B., Donoghue, F. E., and Code, C. F. (1958). Gastroentero$\log y, 34,782$.

Ellis, F. H., Code, C. F., and Olsen, A. M. (1960). Surgery, 48, 155. Olsen, A. M., Schlegel, J. F., and Code, C. F. (1964). F. Amer. med. Ass., 188, 862.

Moersch, H. J., and Camp, J. D. (1934). Ann. Otol. (St. Louis), 43, 1165.

Osgood $\dot{H}$. (1889). Boston med. surg. 7., 120, 401.

Roth, H. P., and Fleshler, B. (1964). Ann. intern. Med., 61, 914

Siegel, C. I. and Hendrix, T. R. (1961). Postgrad. Med., 29, 505.

Siegel, C. I., and Hendrix, T. R. (1961). P.

Soergel, K. H., Zboralske, F. F., and Amberg, J. R. (1964). Ibid., 43. 1472 .

\title{
Normal Confinement: A Domiciliary and Hospital Study
}

\author{
E. A. J. ALMENT,* M.R.C.S., L.R.C.P., M.R.C.o.G. ; A. BARR, † M.SC.(ECON.), PH.D. ; MARJORIE REID, $\ddagger$ M.B., CH.B.
} J. J. A. REID,§ T.D., M.D., B.SC., M.R.C.P., M.R.C.P.ED., D.P.H.

Brit. med. F., 1967, 2, 530-535

In view of the current interest in various patterns of obstetric care a special survey has been made of mothers whose antenatal care and delivery were free from complications. This paper describes the survey results and is divided into three parts, the aspects analysed being certain clinical details, results of early discharge from hospital, and maternal preference for place of confinement.

The material consists of a series of consecutive normal confinements during the winter of 1964-5 at the Barratt Maternity Home, Northampton, and domiciliary confinements in the area of Northamptonshire normally looking to that home for the provision of obstetric services. There were 233 confinements at home and 270 in hospital, recorded by hospital or domiciliary midwives, and the mothers were subsequently interviewed 28 days after confinement, when a questionary dealing with parturition and with antenatal and postnatal experiences was com- pleted. It is worth emphasizing that these interviews were undertaken by health visitors who, in all but a few cases, did not act as midwives, thus reducing the possibility of biased answers which might have been given to the midwives associated with the confinements.

Antenatal and postnatal care was supplied by general practitioners and domiciliary midwives for patients confined at home, and they also shared with hospital personnel in the provision of such care for those with normal pregnancies who had their babies in hospital.

\footnotetext{
- Consultant Obstetrician and Gynaecologist, Northampton Genera Hospital.

t Statistician, Oxford Regional Hospital Board.

¥ Medical Officer, Northamptonshire C.C.

5 County Medical Officer of Health, Northamptonshire C.C.
} 


\section{Some Clinical Comparisons between Hospital and Domiciliary Confinement}

Comparisons of the domiciliary and hospital patients were made in respect of duration of antenatal care, length of labour, birthweight of the baby, perineal repair, the postnatal taking of iron, breast-feeding, and illness of mother and baby against the background of social class and number of previous pregnancies, as these two factors are of particular significance in any consideration of obstetric care.

The hospital sample was biased towards the upper social classes, $16 \%$ of the domiciliary group being in social classes I and II compared with $24 \%$ in the hospital series, and this difference was greater than could easily have arisen by chance at the conventional level of probability $(P=5 \%)$, the criterion used throughout the analysis. Most of this difference occurred in social class $I$, in which there were proportionately three times as many cases in hospital as at home, in contrast to approximately equal numbers in each of the other social groups. Moreover, the local hospital admissions policy favours mothers having their first and fourth or subsequent children, so that it is not surprising to find that only $40 \%$ of mothers with one to three previous children were confined in hospital, compared with $81 \%$ of the nulliparous and $68 \%$ of those having their fifth or subsequent confinement.

\section{Antenatal Care}

Of the 402 women for whom the duration of antenatal care was known, $29 \%$ attended before the 12 th week, $76 \%$ before the 20 th week, and $89 \%$ by the 26 th week. On average, domiciliary patients attended for antenatal care a fortnight earkier than hospital patients. There was little difference between social classes and between nulliparae and multiparae. Women of high parity (four or more previous pregnancies) were slowest in obtaining care ; $52 \%$ of mothers of such parity who were confined in hospital did not obtain antenatal care until after the 20 th week, and this might be one of the reasons for the relatively low proportion (68\%) of these women obtaining hospital beds. Whether members of this group postpone visiting their general practitioner in order to avoid hospital confinement, because of pressure of work, or for some other reason is not known.

\section{Length of Labour}

The average duration of labour for domiciliary patients was 9.6 hours (S.D. 8.3 hours) compared with 10.5 hours (S.D. 8.3 hours) for hospital patients. These differences are not statistically significant. As expected, the duration of labour was longer for nulliparae than for multiparae, but there was little or no difference between hospital and domiciliary patients when standardized for parity.

\section{Birth Weight}

Babies of mothers in social classes I and II tended on average to be heavier than those of mothers in social classes IV and V, but the difference was not great. Similarly, birth weight tended to increase with parity up to two previous pregnancies.

\section{Perineal Repair}

A significantly larger proportion of women in hospital (46\%) had perineal repair (including that resulting from episiotomy) compared with those confined at home $(31 \%)$. There was a marked social-class gradient for both series (Table I), the proportion in social class I being more than double that for social class V. Perineal repair also varied with the number of previous pregnancies. Approximately two-thirds of all nulliparae required perineal repair ; for one to three previous pregnancies the proportion was a third ; while for women with four or more previous births it was approximately $5 \%$. The proportion of women with one to three previous pregnancies having perineal repair was the same for domiciliary and hospital confinements, but it was much higher for nulliparae delivered in hospital $(72 \%)$ than for those delivered at home (44\%).

TABle I.-Number and Percentage of Patients with Perineal Repair by Social Class and Place of Confinement

\begin{tabular}{|c|c|c|c|c|c|c|}
\hline \multirow{2}{*}{ Social Class } & \multicolumn{2}{|c|}{ Domiciliary } & \multicolumn{2}{|c|}{ Hospital } & \multicolumn{2}{|c|}{ Total } \\
\hline & No. & $\%$ & No. & $\%$ & No. & $\%$ \\
\hline $\begin{array}{c}\text { I } \\
\text { III } \\
\text { IV } \\
\text { Not known }\end{array}$ & $\begin{array}{r}3 \\
11 \\
46 \\
8 \\
2 \\
1\end{array}$ & $\begin{array}{l}42 \cdot 9 \\
36 \cdot 7 \\
30 \cdot 7 \\
25 \cdot 0 \\
18 \cdot 2 \\
-\end{array}$ & $\begin{array}{r}12 \\
23 \\
69 \\
10 \\
3 \\
7\end{array}$ & $\begin{array}{l}52 \cdot 2 \\
53 \cdot 5 \\
46 \cdot 9 \\
31 \cdot 3 \\
21 \cdot 4 \\
-\end{array}$ & $\begin{array}{r}15 \\
34 \\
115 \\
18 \\
5 \\
8\end{array}$ & $\begin{array}{l}50 \cdot 0 \\
46 \cdot 6 \\
38 \cdot 6 \\
28 \cdot 1 \\
20 \cdot 0 \\
-\end{array}$ \\
\hline All & 71 & $30 \cdot 5$ & 124 & $45 \cdot 9$ & 195 & $38 \cdot 8$ \\
\hline
\end{tabular}

\section{Iron}

Approximately half of all mothers in the survey were found to be taking iron regularly at 28 days, and proportionately more hospital $(54 \%)$ than domiciliary $(46 \%)$ patients did so, though this difference could easily have arisen by chance. The proportion declined from social classes I and II to the other end of the scale, and this held good for both domiciliary and hospital cases. It also declined with increasing parity in the case of hospital patients, whereas the reverse held true in domiciliary births.

\section{Breast-feeding}

The proportion of babies delivered at home who were fully breast-fed at 10 days ( $49 \%$ ) was comparable to that for hospital deliveries at the time of discharge $(47 \%)$, while at 28 days the corresponding figures were $31 \%$ and $22 \%$. Some important differences between the two groups of patients and between the social classes in relation to breast-feeding are brought out

TABLB II.-Number and Percentage of Babies Fully Breast-fed at 10 Days or Discharge and 28 Days, by Place of Confinement and Social Class

\begin{tabular}{|c|c|c|c|c|c|c|c|c|}
\hline \multirow{3}{*}{ Social Class } & \multicolumn{4}{|c|}{ Domiciliary } & \multicolumn{4}{|c|}{ Hospital } \\
\hline & \multicolumn{2}{|c|}{10 days } & \multicolumn{2}{|c|}{28 days } & \multicolumn{2}{|c|}{ Discharge } & \multicolumn{2}{|c|}{28 days } \\
\hline & No. & $\%$ & No. & $\%$ & No. & $\%$ & No. & $\%$ \\
\hline $\begin{array}{c}I \text { and II } \\
\text { III } \\
\text { IV and V } \\
\text { Not known }\end{array}$ & $\begin{array}{r}29 \\
70 \\
13 \\
1\end{array}$ & $\begin{array}{l}78 \cdot 4 \\
46 \cdot 7 \\
30 \cdot 2 \\
-\end{array}$ & $\begin{array}{r}18 \\
49 \\
6 \\
-\end{array}$ & $\begin{array}{l}48 \cdot 6 \\
32 \cdot 7 \\
14 \cdot 0 \\
-\end{array}$ & $\begin{array}{r}34 \\
72 \\
19 \\
1\end{array}$ & $\begin{array}{l}51.5 \\
48.6 \\
41.3 \\
-\end{array}$ & $\begin{array}{r}25 \\
29 \\
4 \\
-\end{array}$ & $\begin{array}{r}37 \cdot 9 \\
19 \cdot 6 \\
8 \cdot 7 \\
\end{array}$ \\
\hline Total & 113 & $48 \cdot 5$ & 73 & $31 \cdot 3$ & 126 & $46 \cdot 7$ & 58 & $21 \cdot 5$ \\
\hline
\end{tabular}

TABLE III.-Number and Percentage of Mothers Who Were Full Breast-feeding or Whose Lactation was Actively Suppressed at 10
Days for Domiciliary Confinements and Discharge for Hospital Confinements According to Number of Previous Pregnancies

\begin{tabular}{c|c|c|c|c|c|c}
\hline $\begin{array}{c}\text { No. of } \\
\text { Previous } \\
\text { Pregnancies }\end{array}$ & \multicolumn{2}{|c|}{ Domiciliary } & \multicolumn{2}{|c|}{ Hospital } & \multicolumn{2}{|c|}{ Total } \\
\cline { 2 - 3 } \cline { 5 - 6 } & No. & $\%$ & No. & $\%$ & No. & $\%$ \\
\hline
\end{tabular}

\begin{tabular}{|c|c|c|c|c|c|c|}
\hline \multicolumn{7}{|c|}{ Fully breast-feeding } \\
\hline $\begin{array}{c}0 \\
1-3 \\
4+\end{array}$ & $\begin{array}{r}14 \\
96 \\
3 \\
\end{array}$ & $\begin{array}{l}56.0 \\
49.7 \\
20.0\end{array}$ & $\begin{array}{l}56 \\
58 \\
12\end{array}$ & $\begin{array}{l}51.9 \\
45.0 \\
37.5\end{array}$ & $\begin{array}{r}70 \\
154 \\
15\end{array}$ & $\begin{array}{l}52.6 \\
47.8 \\
31.9\end{array}$ \\
\hline All & 113 & $48 \cdot 5$ & 126 & $46 \cdot 7$ & 239 & $47 \cdot 5$ \\
\hline \multicolumn{7}{|c|}{ Lactation actively suppressed } \\
\hline $\begin{array}{c}0 \\
1-3 \\
4+ \\
\text { Not known }\end{array}$ & $\begin{array}{r}8 \\
74 \\
7 \\
- \\
\end{array}$ & $\begin{array}{l}32 \cdot 0 \\
38 \cdot 3 \\
46 \cdot 7 \\
- \\
\end{array}$ & $\begin{array}{r}40 \\
57 \\
17 \\
1 \\
\end{array}$ & $\begin{array}{l}37 \cdot 0 \\
44 \cdot 2 \\
53 \cdot 1 \\
- \\
\end{array}$ & $\begin{array}{r}48 \\
131 \\
24 \\
1\end{array}$ & $\begin{array}{l}36 \cdot 1 \\
40 \cdot 7 \\
51 \cdot 1 \\
-\end{array}$ \\
\hline All & 89 & $38 \cdot 2$ & 115 & $42 \cdot 6$ & 204 & 40.6 \\
\hline
\end{tabular}


in Tables II to IV. A much higher proportion of mothers in social classes I and II confined at home were breast-feeding at 10 days compared with mothers in the same groups at discharge from hospital. In contrast, for social class III the proportion was simiiar for the home and hospital groups, whereas the trend was reversed in social classes IV and V. The difference between domiciliary and hospital patients was greater at 28 days, when a higher proportion of mothers confined at home in each social class were fully breast-feeding their infants. Table IV.-Percentage of Mothers (Domiciliary and Hospital Confine-
ments Combined) Who Were Breast-feeding at 10 Days or Discharge and at 28 Days After Confinement, by Social Class and Parity

\begin{tabular}{|c|c|c|c|c|c|c|c|c|}
\hline \multirow{3}{*}{$\begin{array}{c}\text { No. of } \\
\text { Previous } \\
\text { Pregnancies }\end{array}$} & \multicolumn{8}{|c|}{ Social Class } \\
\hline & \multicolumn{2}{|c|}{ I and II } & \multicolumn{2}{|c|}{ III } & \multicolumn{2}{|c|}{ IV and V } & \multicolumn{2}{|c|}{ All } \\
\hline & No. & $\%$ & No. & $\%$ & No. & $\%$ & No. & $\%$ \\
\hline
\end{tabular}
10 days or discharge

\begin{tabular}{l|r|r|r|r|r|r|r|r}
0 & 12 & $44 \cdot 4$ & 47 & 58.0 & 92 & 52.9 & 68 & $54 \cdot 4$ \\
1 & 25 & 68.4 & 53 & 50.0 & 14 & 43.8 & 92 & 52.8 \\
2 & 19 & 73.0 & 27 & 45.8 & 4 & 30.8 & 50 & 51.0 \\
$3+$ & 7 & 58.3 & 15 & 30.6 & 5 & $19 \cdot 2$ & 27 & 31.0 \\
\hline All & 63 & 62.1 & 142 & $48 \cdot 1$ & 32 & 36.1 & $237^{*}$ & $49 \cdot 0$ \\
\hline
\end{tabular}

\begin{tabular}{l|r|r|r|r|r|r|r|r}
0 & 725.9 & 26 & 32.1 & 4 & 23.5 & 37 & 29.6 \\
1 & 17 & 45.9 & 25 & 23.6 & 4 & 12.5 & 46 & 26.3 \\
2 & 15 & 57.7 & 19 & 32.2 & 1 & 7.7 & 35 & 35.7 \\
$3+$ & 4 & 33.3 & 8 & 16.3 & 1 & 3.8 & 13 & 14.9 \\
\hline All & 43 & 42.2 & 78 & 26.4 & 10 & 11.4 & 131 & 27.0 \\
\hline
\end{tabular}

- In two cases the social class was not known.

As the number of previous children increased, breast-feeding at 10 days declined. The proportion fully breast-fed was slightly higher in domiciliary than in hospital confinements for mothers with up to three previous pregnancies; thereafter hospital confinement appeared to be more highly associated with breast-feeding. Lactation was actively suppressed within 10 days in $41 \%$ of mothers, the comparative figures for domiciliary and hospital confinements being $38 \%$ and $43 \%$ respectively. This practice increased slightly with parity, the tendency being more pronounced for hospital than for domiciliary confinements.

As already shown, social class had a distinct bearing on whether or not the mother breast-fed her baby, and it is of interest to see if these trends are consistent within parity. The numbers are too small for separate analysis of home and hospital confinements, but taking the two groups together there is a well-defined social-class gradient for all but first babies, which was apparent shortly after confinement, as well as at 28 days. The rate at which mothers ceased breast-feeding was more rapid for social classes IV and V, than for I and II, a trend common to each parity.

\section{Illness of Mother and Baby}

The majority of mothers had no illness or complication after confinement ( $85 \%$ of the domiciliary group and $79 \%$ of the hospital cases). The commonest ailments arising in home confinements were breast conditions, including sore and cracked nipples and inflammation, which occurred in $7 \%$ of the total group, and mild respiratory infections, which occurred in $2 \%$. Similar breast conditions arose in $5 \%$ of the hospital patients, while respiratory infections accounted for $4 \%$.

About a quarter of the patients complained of backache, and this applied irrespective of place of confinement. The proportion tended to rise slightly with increasing parity in the hospital group, though for the domiciliary group the trend was in the opposite direction. Backache did not appear to be associated with perineal repair.

In $42 \%$ of the patients red lochia was still present at three weeks, the proportion being slightly higher for hospital (44\%) than for domiciliary confinements $(40 \%)$. Among home con- finements there was practically no difference in relation to the number of previous pregnancies, but for the hospital series the proportion increased from $37 \%$ for women with no previous children to $44 \%$ for women with one to three previous pregnancies, and to $53 \%$ for women of even higher parity.

Direct comparison of the illnesses of babies born at home and in hospital can be misleading, as some conditions-for example, rhesus incompatibility-may lead to a hospital confinement while others-for example, congenital deformity and prematurity-can occur in either place and do not reflect the safety or otherwise of home versus hospital care. If babies with jaundice, congenital deformity, and prematurity are excluded, all but $1 \%$ of the domiciliary-born had no illness at 10 days, compared with $5 \%$ of the hospital-born. At 28 days these figures became $12 \%$ and $20 \%$ respectively, the most common conditions in both groups being minor respiratory and eye infections. Thus the child born at home was less liable to infection during the first four weeks of life.

\section{Early Discharge from Hospital}

Attention was first drawn to the practicability of early discharge of maternity patients in the Bradford experiment (Theobald, 1959, 1962), where selected mothers were sent home 48 hours after delivery. During 1959 and 1960 about 3,000 mothers and babies went home on the second day. No mother died and only nine were readmitted to hospital; while of the babies one died within the first four weeks of life and 13 were readmitted to hospital. There is no evidence that, by these criteria, any mother or baby suffered from being discharged early (Douglas et al., 1961). McEwan (1964) followed up 1,044 mothers who were discharged early in Wolverhampton County Borough and concluded that mortality after discharge from hospital was nonexistent in mothers and small in babies ; that morbidity was low for both; and that neither mortality nor morbidity could be attributed to early discharge. Ethnic group, not duration of stay in hospital, was the more decisive factor in the establishment and maintenance of breast-feeding, though there was a suggestion that a very short stay (nought to three days) might be an advantage in the European. A plea for a more rational approach to the length of the puerperium has been made by Rhodes (1964), who argued that it should be assessed for each woman and her baby and not preordained. Moreover, Rhodes believes that unless there are sound medical reasons for opposing her, a woman's wishes should be respected in this matter just as they are in other branches of medicine. The fact is that for many mothers what is required after confinement is domestic help.

As yet little information is available on the results of early discharge, and for this reason certain data obtained in the study are of special interest. It should be clear that there is no question of an experiment on the basis of allocating patients at random between early or normal discharge. The results therefore reflect the current medical and social policies of the maternity home.

\section{Results}

For the purpose of this analysis early discharge has been arbitrarily defined as a stay of four days or less after confinement. In this sense there were $108(40 \%)$ discharged "early," leaving $162(60 \%)$ who were discharged "late."

An analysis by reason for admission showed that emergency admission was more prevalent among the early-discharge group. This is not surprising, since the Barratt Maternity Home is fully booked and emergency admissions can be accepted only for a short time. Nulliparity and social reasons were less frequent causes of admission among those discharged early.

Of the 270 mothers, $118(44 \%)$ were planned during the antenatal period to have an early discharge, and $79(67 \%)$ of 
these remained in hospital for four days or less. . A further 29 mothers had an unplanned early discharge:

The early- and late-discharge groups did not differ in respect of social class, time at which antenatal care was first sought, length of labour, perineal repair, the taking of iron during the puerperium, or the birth weight of the infant. As would be expected, there was an important difference in respect of parity $74 \%$ of early discharges were multiparous, compared with $50 \%$ of the remainder, the difference being unlikely to have arisen by chance.

The most important criteria are, of course, the mortality and the morbidity experience of the mothers and babies in the two groups, which in the present instance was confined to the first 28 days after confinement. One premature baby died in hospital, having never been discharged. While the babies were in hospital there was little difference in the morbidity of those discharged early or late- $84 \%$ of the babies in the earlydischarge group had no illness compared with $86 \%$ among the later discharges. The illnesses after discharge from hospital were mostly of minor degree, and babies discharged early tended to have more respiratory complaints. An assessment made by the health visitor indicated that the baby's progress was satisfactory for $97 \%$ of the early and $99 \%$ of the late discharges; this difference could easily have arisen by chance.

The pattern was much the same for the mother. Threequarters of the early discharges had no illness as compared with four-fifths of the late discharges. The health visitor's assessment of the mother's fitness at 28 days indicated that $10 \%$ of the early discharges were not fully fit, compared with $7 \%$ for the other group; again these differences could have arisen fortuitously.

Breast-feeding did not seem to be affected by length of stay (Table V). The pattern was similar for the suppression of lactation; of the early discharges $40 \%$ had lactation suppressed compared with $44 \%$ of the late discharges.

TABLE V.-Percentage Distribution of Mothers Fully Breast-feeding at Discharge and 28 Days

\begin{tabular}{|c|c|c|c|c|c|}
\hline \multicolumn{3}{|c|}{ Fully Breast-feeding at } & \multirow{2}{*}{$\begin{array}{c}\text { Early Discharge } \\
50.0 \\
23.0\end{array}$} & \multirow{2}{*}{$\frac{\text { Late Discharge }}{4 \begin{array}{c}46.7 \\
21.5\end{array}}$} & \multirow{2}{*}{$\begin{array}{c}\text { Total } \\
\begin{array}{l}48 \cdot 1 \\
22 \cdot 1\end{array}\end{array}$} \\
\hline $\begin{array}{l}\text { Discharge } \\
28 \text { days .. }\end{array}$ & $\because$ & $\because$ & & & \\
\hline Total & $100 \%)$ & $\cdots$ & 108 & 162 & 270 \\
\hline
\end{tabular}

It might be thought that some differences would occur between the two groups in respect of the type of domestic help available or in the length of time it was supplied. Analysis showed, however, that the two groups differed only marginally. Of those discharged early $5 \%$ stated that they had no help, compared with $6 \%$ for the late discharges. Nearly a third of the patients had full-time or part-time help available for a fortnight or more.

The health visitor was asked to state whether, in her opinion, the stay in hospital was of the correct duration. For the early discharges, $86 \%$ were thought to be correct, $13 \%$ too short, and $1 \%$ too long, while for the late discharges the comparable figures were $93 \%, 7 \%$, and $1 \%$ respectively. These differences could easily have occurred by chance (comparing the "correct" and "incorrect" stay in the two groups, $\chi^{2}=2.24$; D.F. $=1$; $0.2>\mathrm{P}>0.1$ ).

The length of stay preferred by mothers indicated that, for the present confinement, three-quarters of those discharged early were satisfied, while $15 \%$ would have preferred an even shorter stay. In only $9 \%$ did the mother express a preference for a longer stay. For the next confinement, two-thirds of those discharged early would like the same, a fifth would like a shorter stay, and $11 \%$ would prefer a longer stay. On the whole, the short stay was not regarded as a burden by the mothers concerned.

Though the present si:-zple is small, the results confirm other studies (Foster, 1957 ; FitzGerald, 1959; Theobald, 1959,
1962 ; Pinker and Fraser, 1964) which show that an early discharge does not increase the morbidity or mortality of the mother or baby. In this survey the early discharges (defined as a stay of four days or less) included a high proportion of emergency admissions, and it might be expected that this would react unfavourably on the early-discharge group. Even so, the differences between the two groups were negligible, and it seems reasonable to conclude that early discharge after a normal confinement is a safe policy.

There is little doubt that the trend towards shorter stay in maternity hospitals will continue, and, taking account of the present evidence, this is justified. Obviously the shorter the period spent in hospital the closer must be the liaison between the domiciliary and the hospital midwifery service, and cooperation would be facilitated by a joint hospital-domiciliary midwifery service.

\section{Home or Hospital Confinement}

The increasing number of births, the identification of mothers who have a relatively high risk of abnormal pregnancy, and the limited hospital resources available have combined to focus attention on the comparative merits of hospital and home confinement. In some countries, notably America and Sweden, practically all births take place in hospital, and it has been argued that a similar pattern should also apply in this country ; but this is an extreme view unlikely to be accepted generally. The perinatal mortality survey (Butler and Bonham, 1963) showed that, for comparable groups of mothers, the perinatal mortality tended to be lowest among those delivered in specialist hospitals. While it may be desirable from a purely obstetrical viewpoint that all confinements should take place in properly equipped and staffed obstetric units, there are other considerations which should be borne in mind, and one of the most important of these is the mother's preference for place of confinement. Information on this was obtained as part of the present study.

\section{Results}

Each mother was asked where she would like to have her next confinement if she had the choice, and an analysis of the response by parity is given in Table VI. Of the 503 mothers, $317(63 \%)$ expressed preference for home confinements, and $184(37 \%)$ for hospital ; two mothers did not specify. Among those whose present confinement took place at home there was almost complete unanimity of preference $(94 \%)$ for the next confinement to be at home. Of the hospital group, $63 \%$ wanted to return to hospital, leaving $37 \%$ who preferred to be confined at home. Since about three-quarters of deliveries in Northamptonshire take place in hospital (Reid, 1965), approximately half of all mothers appear to prefer home confinement, while half would rather have hospital delivery.

TABLE VI.-Preference for Next Confinement According to Number and Place of Previous Confinements and Place of Last Confinement

\begin{tabular}{|c|c|c|c|c|c|c|}
\hline \multirow{4}{*}{ Previous Confinements } & \multicolumn{6}{|c|}{ Place of This Confinement } \\
\hline & \multicolumn{3}{|c|}{ Home } & \multicolumn{3}{|c|}{ Hospital } \\
\hline & \multicolumn{2}{|c|}{$\begin{array}{l}\text { Prefer Next } \\
\text { Confinement }\end{array}$} & \multirow[b]{2}{*}{ Total } & \multicolumn{2}{|c|}{$\begin{array}{l}\text { Prefer Next } \\
\text { Confinement }\end{array}$} & \multirow[b]{2}{*}{ Total } \\
\hline & $\begin{array}{c}\text { At } \\
\text { Home }\end{array}$ & $\begin{array}{l}\text { In } \\
\text { Hos- } \\
\text { pital }\end{array}$ & & At & $\underset{\text { Hospital }}{\text { In }}$ & \\
\hline 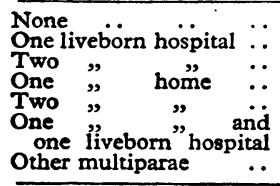 & $\begin{array}{l}24 \\
71 \\
23 \\
29 \\
10 \\
26 \\
36\end{array}$ & $\begin{array}{l}1 \\
6 \\
4 \\
\\
3\end{array}$ & $\begin{array}{l}25 \\
77 \\
27 \\
29 \\
10 \\
26 \\
39\end{array}$ & $\begin{array}{r}35 \\
20 \\
7 \\
5 \\
- \\
4 \\
27 \\
\end{array}$ & $\begin{array}{r}73 \\
37 \\
18 \\
7 \\
1 \\
2 \\
32 \\
\end{array}$ & $\begin{array}{c}108^{*} \\
57^{*} \\
25 \\
12 \\
1 \\
6 \\
59\end{array}$ \\
\hline Total patients & 219 & 14 & 233 & 98 & 170 & 268 \\
\hline
\end{tabular}

- Total excludes one patient where preference was not stated. 
Not all the women in the survey had had both a home and a hospital delivery, so these proportions could be affected by limited experience. Because of this, it is worth considering only those mothers who had at least one confinement at home and one in hospital. There were 212 such women, and 174 $(82 \%)$ of them said they would prefer to have their confinement at home, while $38(18 \%)$ chose hospital. In other words, among women with experience of confinements at home and in hospital the preference for home confinement outnumbers hospital confinement by a ratio of five to one. Eleven mothers had had at least one previous stillbirth, and seven of them expressed preference for their next confinement to be at home, while four preferred hospital. The ratio of approximately two to one is not as great as for mothers in general, suggesting that previous stillbirth may exert some influence on the choice.

The choice between home and hospital for tho:; confined in hospital did not seem to be influenced by the presence of other children in the family, for Table VI shows that 35 out of 109 (32\%) of the primiparae preferred home confinement compared with 63 out of 161 (39\%) of the multiparae. Treatment and care in hospital could have a bearing on future preference, but there is no simple index by which this can be measured. An analysis of perineal repair (Table VII) showed that this procedure was not a discriminating factor. Duration of stay gave a similar result, most mothers being satisfied with the length of stay they had experienced. Of mothers discharged earlythat is, within four days of delivery-52\% would prefer to have their next babies at home. The high proportion is not surprising, since the early discharge was usually planned in advance, and presumably this group consisted of women anxious to return home as soon as possible. Analysis by social class failed to show any differences that could not easily have arisen by chance (Table VIII). It is worth pointing out, however, that the proportion preferring home confinements was consistently higher in social classes III, IV, and V than for social classes I and II. Other variables (age of patient, complications in mother and/or baby, distance from hospital, and stage of pregnancy on first consulting the general practitioner) were considered in a similar way, but none showed any significant association with the place where the mother preferred to be confined.

TABLE VII.-Number of Mothers Confined in Hospital by Preference for Next Confinement, Partiy, and Perineal Repair. (Figures in Parentheses Indicate Percentages)

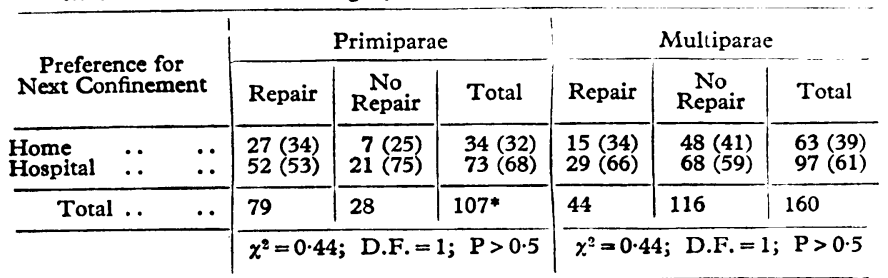

- Excludes one patient where information was incomplete.

TABLE VIII.-Preference for Next Confinement According to Social Class

\begin{tabular}{c|c|c|c|c}
\hline Social Class & \multicolumn{2}{|c|}{ All Patients } & Hospital Confinement \\
\cline { 2 - 5 } & No. & $\begin{array}{c}\text { \% Preferring } \\
\text { Home } \\
\text { Confinement }\end{array}$ & No. & $\begin{array}{c}\text { \% Preferring } \\
\text { Home } \\
\text { Confinement }\end{array}$ \\
\hline I and II & 103 & 54 & 66 & 32 \\
III V & 298 & 67 & 148 & 39 \\
Not known & 13 & 65 & 10 & 39 \\
\hline Total & 503 & 63 & 270 & 36 \\
\hline
\end{tabular}

\section{Factors Influencing Choice}

The domiciliary and hospital maternity services in Northamptonshire are reasonably satisfactory, and there is no cause to believe that adequacy or standard of service influenced the patient's choice. The finding that roughly half of the women would prefer a home confinement, with an even higher proportion among mothers who have had at least one confinement at home and one in hospital, is interesting. No attempt was made to evaluate the reasons underlying mothers' preference for home or hospital confinement, but it may be assumed that these are likely to lie in the social rather than in the obstetric sphere. It is not unnatural that many women should prefer to be delivered at home, where they are in familiar surroundings. There they have the company of their families and do not have to leave them at a critical phase in their confinements in order to enter hospital. Factors such as restriction of visiting and the absence of her husband during the delivery may also have a bearing on the mother's outlook, as may an understaffed and overworked maternity unit.

The question of the extent to which hospital provision should be made for obstetric purposes requires consideration. Confinement at home is cheaper, though, as the Cranbrook Committee (Ministry of Health, 1959) pointed out, it is difficult to obtain strictly comparable costs. In the financial year 1964-5 the average cost of the local authority midwifery service for each home confinement was $£ 261 \mathrm{~s}$. 0d. in the case of English and Welsh counties, and $£ 2014 \mathrm{~s}$. Od. for county boroughs (Institute of Municipal Treasurers and Accountants, 1965). These figures are exclusive of any relevant expenditure on the home help service, but as this applies to only a minority of confinements and is, in any case, subject to some degree of repayment by patients, the effect on local health authority midwifery costs is likely to be small. The national average for the hospitals in the Ministry of Health's main costing scheme was $£ 4516 \mathrm{~s}$. $0 \mathrm{~d}$. per obstetric case during the same financial year (Ministry of Health, 1965), and was thus substantially higher than in domiciliary midwifery. It would therefore appear to be both obstetrically and financially sensible to make the best possible use of the specialist facilities available in hospital by trying to ensure that they are utilized by those in greatest need of them.

More precise methods for evaluating obstetric risk may become available (Feldstein, 1965), but at the present time a reasonable approach would seem to be that adopted by the Cranbrook Committee-namely, that all women with medical or social need should have priority for hospital beds, the remainder being confined either at home or in hospital according to the wishes of the mothers and the local availability of obstetric resources. In areas where these exist, an alternative to home confinement in uncomplicated low-risk cases is delivery in a general-practitioner maternity unit, and in Northamptonshire some $18 \%$ of confinements took place in such units in 1965.

Where delivery in a specialist obstetric unit is indicated a possible approach to the task of balancing obstetrical needs against maternal wishes would be to have a service in which midwives could function both in patients' own homes and in hospital, for it must be remembered that at $70 \%$ of all confinements, whether at home, in general-practitioner units, or in hospital, the midwife either conducts the delivery herself or is the most senior person present (Butler and Bonham, 1963). Dorsiciliary midwives would be able to admit their patients to hospital and to attend them there during their confinements, returning them home in most cases within 48 hours of delivery. This would have the advantage of minimizing the mother's absence from home, enabling her to be delivered by someone well known to her, providing a high degree of obstetric safety, ensuring a flexible hospital discharge policy, adding to the professional satisfaction of domiciliary midwives, and making the most economical use of the limited national supply of such personnel. It would have the particular merit of encouraging a greater proportion of the more highly parous women to accept hospital confinement; for, where previous births have taken place at home under the care of a known and trusted domiciliary midwife, some mothers refuse to consider hospital confinement, despite the sound obstetric reasons for urging this. The policy 
advocated has been successfully tried in a small town with its own maternity unit in Northamptonshire and is now being introduced in the Barratt Maternity Home itself.

Finally, it should be pointed out that in the area covered by the study a large proportion of antenatal care is provided by family doctors, and all those on the obstetric list have access to the various general-practitioner maternity units. Since acceptance on the obstetric list for new applicants is now almost entirely confined to those with postgraduate obstetric experience, it is clear that the future general-practitioner maternity service will show an increasing proportion of general-practitioner obstetricians with special interest and skill. Just as midwives should have access, so such general-practitioner obstetricians should be provided with every facility to follow the care of their patients in specialist obstetric units.

\section{Summary}

A survey of 503 (233 domiciliary and 270 hospital) normal confinements has been analysed with regard to three aspects of obstetric care.

Almost a quarter of the women delayed seeking antenatal care until the 20th week of pregnancy or later, and this state of affairs was particularly marked among those of high parity who were subsequently confined in hospital.

Perineal repair was more commonly necessary in hospital patients, and the need for it diminished with descending social class and increasing parity. Only about half of the mothers were found to be taking iron regularly 28 days after confinement.

By 28 days the proportion of mothers in each social class who were breast-feeding their babies was higher in those who had been confined at home than in those delivered in hospital, though such feeding diminished with descending social class and with increasing parity. With the exception of first babies, there was a social-class gradient for each parity, both at 10 and 28 days after delivery.

Among mothers there appeared to be little to choose between hospital and home delivery so far as illness in the first 28 days after confinement was concerned, whereas in the case of infants the advantage appeared to lie on the side of home confinement.

On the question of early discharge from hospital, a follow-up of mothers and babies discharged within four days of delivery showed that they had slightly more minor illness compared with those discharged later, but the difference could easily be attributable to chance.

In view of the increasing trend towards shorter hospital stay, it is suggested that a combined hospital-domiciliary midwifery service is required, in which midwives would have continuous supervision of mothers both at home and in hospital.

An investigation into choice of place of confinement showed that $63 \%$ of all mothers would prefer to have their next confinement at home, the percentages for those delivered at home or in hospital being $94 \%$ and $37 \%$ respectively. Bearing in mind that $75 \%$ of the mothers in the area have hospital confinements, preference for a home or hospital confinement is equally divided. This again points to the conclusion that a combined hospital and domiciliary midwifery service would offer benefits from all points of view.

Thanks are due to the staff of the Barratt Maternity Home and to the midwives and health visitors of Northamptonshire County Council for undertaking the field work of this study, and to the staff of the Statistical Unit of the Oxford Regional Hospital Board for the analysis.

\section{REFERENCES}

Butler, N. R., and Bonham, D. G. (1963). Perinatal Mortality. London. Douglas, J., Edgar, W., and Horne, K. (1961). Med. Offr, 106, 333. Feldstein, M. S. (1965). Opl Res. Q., 16, 65 . FitzGerald, T. B. (1959). Lancet, 1, 403.

Foster, D. S. (1957). Brit. med. \%., 1, 1120.

Institute of Municipal Treasurers and Accountants (1965). Local Health Services Statistics 1963-1964. London.
S

McEwan, E. D. (1964). Lancet, 2 , 744.

Ministry of Health (1959). Report of the Maternity Services Committee (Cranbrook Committee). H.M.S.O., London.
(1965). Hort

(1965). Hospital Costing Returns. Pt. 1, 1964-1965. H.M.S.O., London.

Pinker, G. D., and Fraser, A. C. (1964). Brit. med. 7., 2, 99.

Reid, J. J. A. (1965). The Health of Northamptonshire in 1964.

Rhodes, P. (1964). Lancet, 2, 746.

Theobald, G. W. (1959). Brit. med. 7., 2, 1364.

- (1962). Lancet, 1, 735 .

\title{
Dosage of Gentamicin for Pseudomonas Infections
}

\author{
J. H. DARRELL,* M.B., D.C.H., M.C.PATH. ; PAMELA M. WATERWORTH,† F.I.M.L.T.
}

Brit. med. F., 1967, 2, 535-537

Gentamicin is a recently described addition to the aminoglycoside group of antibiotics, which includes streptomycin, neomycin, and kanamycin (Weinstein et al., 1963). It is active in vitro against a wide range of Gram-negative and Grampositive bacteria, including Pseudomonas aeruginosa and neomycin-resistant staphylococci (Barber and Waterworth, 1966), streptococci being the only common pathogens showing uniform moderate-to-high resistance. Like other members of the group it is ototoxic, and vestibular damage has been reported in patients with impaired renal function (Bulger et al., 1963 ; Sweedler et al., 1963 ; Jao and Jackson, 1964).

The recommended dose is only $40 \mathrm{mg}$. twice daily. The observations recorded here were routine clinical investigations,

\footnotetext{
- Lecturer, Department of Bacteriology, Royal Postgraduate Medical School, London W.12; Honorary Consultant Bacteriologist,

t Research Assistant, Department of Bacteriology, Royal Postgraduate

and the purpose of this preliminary report is to suggest that this dosage is inadequate for the treatment of pseudomonas infections and is encouraging the development of resistance.

\section{Materials and Methods}

All patients were receiving gentamicin for infections due to Ps. aeruginosa known to be at least moderately sensitive to a $10-\mu \mathrm{g}$. disc.

Minimum inhibitory concentrations were done by the plate dilution technique with Oxoid blood agar base No. 2 and a light inoculum (a 1 in 500 dilution of an overnight broth culture).

Gentamicin assays were done by the vertical diffusion technique of Mitchison and Spicer (1949), the Oxford staphylococcus being used. Penicillin when present was inactivated by penicillinase, and when erythromycin or methicillin was present 